A AUTORA

Cleoni Fanelli Inácio

Professora da Escola Estadual de Ensino

Fundamental Lizete Paulino Teixeira, Franca/SP

\title{
NA ESCOLA COM AS HISTÓRIAS EM QUADRINHOS
}

Turma da Mônica é pretexto para desenvolver leitura, escrita e habilidades comunicativas

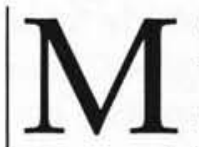

otivada pela vontade de reverter o quadro de desinteresse e total falta de motivação dos meus alunos pela leitura e escrita, resolvi trabalhar com histórias em quadrinhos por perceber que eram elas do agrado da maioria das crianças.

$\mathrm{O}$ trabalho se desenvolveu num período de dois meses, em que cada atividade ia dando seqüência àquela desenvolvida anteriormente.

Começamos com o cantinho de leitu$r a$. Horário reservado diariamente e durante o qual as crianças se dedicaram à leitura de gibis em rodinhas formadas ao ar livre, no pátio de nossa escola.

As crianças pesquisaram sobre a vida e obra de Maurício de Souza, através de material selecionado por mim (revistas, jornais, livros...) e alguns trazidos pelas próprias crianças.

Foi aberto um painel para se discutir sobre a vida e obra de Maurício de Sou- $\mathrm{za}$, levando as crianças a pensarem sobre a possibilidade de qualquer criança desenvolver-se profissionalmente, e ser bem sucedida na vida, através da determinação, da confiança em si mesma e do trabalho sério.

A fim de conhecerem melhor os personagens e o trabalho do autor, assistiram a uma seqüência de curtas metragens dos desenhos animados Turma da Môni$c a$, no vídeo da escola. Posteriormente foi formado um círculo de discussão, onde pudemos analisar as características físicas e psicológicas de cada personagem (Mônica, Cebolinha, Cascão, Magali...) baseados no filme e nas várias historinhas lidas.

Em folhas de papel, as crianças registraram as características de cada personagem, colando a gravura das embalagens vazias de salgadinhos da turma da Mônica, recolhidas no pátio da escola, durante os recreios. 
Em grupos, as crianças trabalharam selecionando os diferentes tipos de balões existentes nos quadrinhos e analisando suas funções e significados específicos.

Foi dada uma história para cada dupla, a partir da qual elas deveriam criar outros balões dentro do contexto, com a maior variedade possível, colocando em prática o que viram na atividade anterior.

Selecionei algumas histórias que possuíam quase nenhum texto escrito, cuja compreensão se baseava toda nos desenhos. As crianças, em pequenos grupos, deveriam analisar a expressão dos personagens e o cenário onde se passava a história, relacionando a ausência da escrita com a importância da imagem (diferentes formas de comunicação) nas histórias em quadrinhos.

Baseados numa história lida, fizemos, coletivamente, a reprodução desta história na forma de um texto narrativo, levando-se em conta a necessidade de registrar com detalhes as respostas às questões: quando, onde, como, visto que, na narrativa, não se têm os recursos da imagem, presentes nas histórias em quadrinhos.

\section{CRIANÇAS AUTORAS DAS HISTÓRIAS}

Depois, em duplas, as crianças puderam, em outros momentos, fazer outras transcrições de histórias na forma narrativa. Os trabalhos foram fixados em mural e reservado um espaço para leitura dos textos dos colegas, já que ninguém se vê motivado a escrever quando sabe que seus escritos não serão lidos por ninguém além dele mesmo.
Numa outra atividade desenvolvida durante o projeto, as crianças receberam apenas a primeira folha de uma história e a partir daí criaram o restante dela. Depois, elas puderam comparar o seu texto com o original, numa atividade em que se exercita a criatividade, a escrita e a leitura de forma dinâmica, prazerosa e divertida.

Depois de toda essa familiaridade com as obras de Maurício de Souza, as crianças escreveram cartas para ele, nas quais descreveram as atividades desenvolvidas, falaram de suas opiniões, seus desejos etc. Neste processo, foi feita a visita ao correio da cidade e, posteriormente, recebemos uma gentil resposta da equipe de produções Maurício de Souza, o que muito alegrou a turma.

Outra atividade desenvolvida foi a análise da fala do personagem Chico Bento. As questões diziam respeito a: por que ele fala assim? por que a fala dele é diferente? quem fala assim? como se fala em nosso meio? Depois, mostramos para as crianças uma entrevista, feita pelo apresentador Faustão, com o jornalista William Bonner. As mesmas perguntas foram feitas em relação aos modos de falar do jornalista. As respostas obtidas ilustraram a reflexão sobre as diferentes formas de se falar. O nível popular e o outro mais próximo do formal, no caso a fala do jornalista entrevistado.

Vimos também exemplos da fala de cariocas, gaúchos, cearenses, baianos etc. e concluímos pela existência de grande variação lingüística. 
Fizemos também um debate a respeito da fala chamada culta e sua aplicabilidade em determinadas situações e o papel da escola para o conhecimento da mesma, sempre deixando claro que não é uma questão de fala correta ou incorreta, mas sim da aplicabilidade desta variedade lingüística em determinadas situações (carta a um amigo, carta pedindo um emprego).

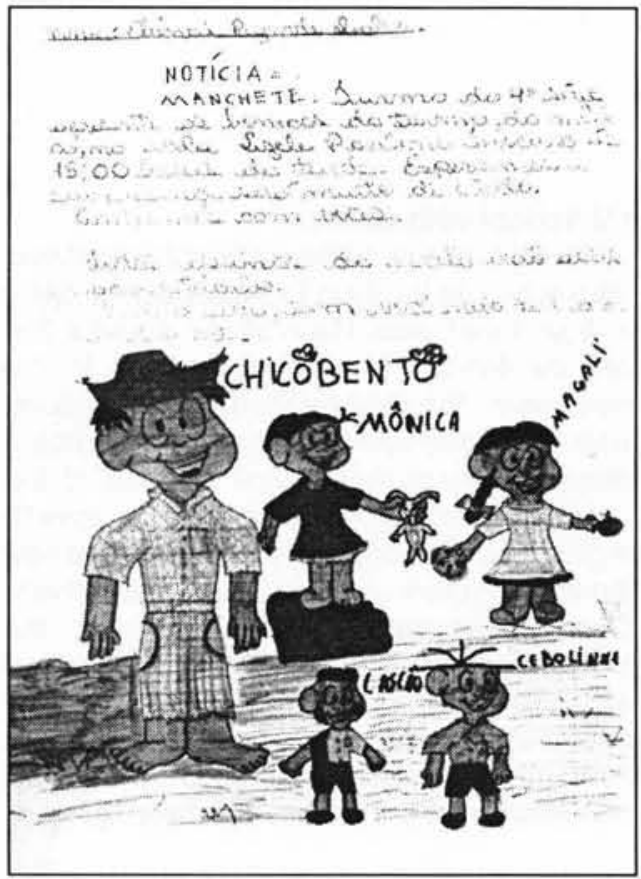

As crianças desenvolveram a atividade de reescrever as falas do personagem Chico Bento, contida nos balões das histórias em quadrinhos, para uma fala diferente, mais próxima à formal. Cada grupo recebeu uma história diferente, previamente selecionada por mim, cada uma abordando um tema diferente (ética, saúde, pluralidade cultural, educação ambiental: os chamados Temas transversais). A partir do contexto, com base num roteiro recebido, elas discutiram o assun- to, concluíram e depois cada grupo o passou para o conjunto dos colegas da classe, num grande painel.

Numa outra atividade, a classe confeccionou bonecos de jornal. Um grupo ficou encarregado de fazer o figurino, caracterizando-os como personagens das histórias em quadrinhos. O outro grupo se encarregou do cenário onde foi feita a encenação dos personagens, com direito a sonoplastia e tudo. Apresentaram para os alunos das outras classes da escola. Tudo foi registrado em fita de vídeo. Foi uma atividade muito movimentada e com a qual a criançada se envolveu bastante.

\section{Concomitantemente à execução} da atividade anterior, os alunos redigiram notícias para o jornal, divulgando a apresentação do teatro de bonecos, convidando a turma da escola para assistir.

Neste período, trabalhamos também toda a estrutura do jornal e da notícia (o que, quando, onde, como, por quê), culminando com a redação da notícia sobre a apresentação do teatro de bonecos. A notícia foi fixada no mural da escola.

Depois da apresentação do teatro, as crianças voltaram a escrever para o jornal mural divulgando o sucesso.

Numa outra atividade, os alunos saíram às ruas para fazer uma enquete sobre a opinião das pessoas a respeito das histórias em quadrinhos.

Como última atividade, fizemos a escrita espontânea, momento em que cada um pôde escrever sobre a experiência vi- 
vida em todas as atividades. Eu aproveitei para fazer a minha escrita espontânea também.

Como se vê, um único material, no caso os gibis, pode ser explorado numa sala de aula de forma significativa e dinâmica: através deles as crianças lêem, escrevem, criam, pesquisam, dramatizam, entrevistam. Sem ao menos se darem conta, do ponto de vis- ta pedagógico, de tudo o que estão fazendo, uma vez que, para elas, o que importa é o momento, a significação daquilo que fazem e o prazer com que fazem, vendo resultados, respostas para suas ações. É assim que eu, como educadora, entendo a arte de interagir com a educação, no papel de guia e conselheira no processo de aprendizagem desenvolvido pelos alunos.
Resuma. Professor da rede pública de ensino conta sua experiência pedagógica desenvolvendo projeto que usa histórias em quadrinhos da Turma da Mônica, de Maurício de Souza, em sala de aula. As crianças lêem os gibis, assistem aos desenhos animados, pesquisam sobre o seu criador, discutem as características dos personagens e os diferentes niveis ou registros de fala que aparecem, criam novas histórias, passam à escrita e narram. Além da narrativa da história em quadrinhos, o professor trabalhou com as crianças noções de texto jornalístico, à medida que a elas foi proposto divulgar o trabalho produzido, no jornal mural da escola, convidando os colegas para a apresentação teatral das histórias criadas.

Palavras-chave histórias em quadrinhos, projeto pedagógico, Turma da Mônica, professor, ensino fundamental

\section{(At school with comics)}

Abstract. A teacher of the public school network talks about her teaching experience developing a project that uses Maurício de Souza's Turma da Mônica funnybook stories in the classroom. The children read the funnybooks, watch the cartoons, research their creator, discuss the characteristics of each of the characters and the different levels or speech registrations that appear; they then create new stories, put them in writing and narrate them. Over and beyond the story's narrative, the teacher worked with notions in journalistic text with the children and, as proposed, they divulged the work they produced in the school's bulletin and invited their friends to the theatrical presentation of the stories that were created.

Key words. cartoons, teaching project, Turma da Mónica, teacher, elementary school 